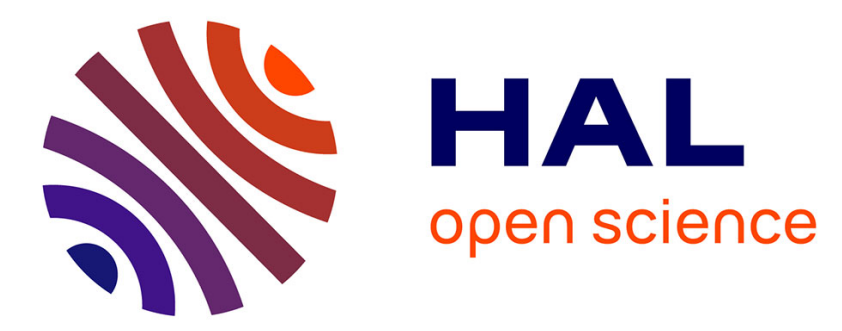

\title{
High robustness PNP-based structure for the ESD protection of high voltage I/Os in an advanced smart power technology
}

Philippe Renaud, Amaury Gendron, Marise Bafleur, Nicolas Nolhier

\section{- To cite this version:}

Philippe Renaud, Amaury Gendron, Marise Bafleur, Nicolas Nolhier. High robustness PNP-based structure for the ESD protection of high voltage I/Os in an advanced smart power technology. Bipolar/BiCMOS Circuits and Technology Meeting (BCTM), Oct 2007, BOSTON, United States. pp.359. hal-00195362

\section{HAL Id: hal-00195362 \\ https://hal.science/hal-00195362}

Submitted on 10 Dec 2007

HAL is a multi-disciplinary open access archive for the deposit and dissemination of scientific research documents, whether they are published or not. The documents may come from teaching and research institutions in France or abroad, or from public or private research centers.
L'archive ouverte pluridisciplinaire HAL, est destinée au dépôt et à la diffusion de documents scientifiques de niveau recherche, publiés ou non, émanant des établissements d'enseignement et de recherche français ou étrangers, des laboratoires publics ou privés. 


\title{
High robustness PNP-based structure for the ESD protection of high voltage I/Os in an advanced smart power technology
}

\author{
P. Renaud ${ }^{1}$, A. Gendron ${ }^{1,3}$, M. Bafleur ${ }^{2}$, N. Nolhier ${ }^{2}$ \\ ${ }^{1}$ Freescale Semiconductor, TOULOUSE, FRANCE \\ ${ }^{2}$ LAAS-CNRS, Université de Toulouse, TOULOUSE, FRANCE \\ ${ }^{3}$ Now with Freescale Semiconductor, TEMPE AZ 85284, USA
}

\begin{abstract}
A new device dedicated to the ESD protection of high voltage $\mathrm{I} / \mathrm{Os}$ is presented. In addition to the use of specific design guidelines, the concept consists in coupling an open-base lateral PNP with a vertical avalanche diode within the same structure to obtain a non-snapback behavior together with very good $R_{O N}$ capabilities $(\sim 1 \Omega)$. The protection of high voltage I/Os with a narrow ESD design window ranging from $80 \mathrm{~V}$ to $100 \mathrm{~V}$ can be implemented in a reduced surface of $151 * 140 \mu \mathrm{m}^{2}$, which represents a state-of-the-art breakthrough.
\end{abstract}

Index Terms - ESD protection, High voltage I/Os, smart power technology, PNP bipolar transistor.

\section{INTRODUCTION}

A major challenge in smart power technologies is the ESD protection of high voltage $\mathrm{I} / \mathrm{Os}$ in applications such as the automotive and PowerOver-the-Ethernet markets. To avoid latch-up issues, the clamping voltage of the ESD protection device should be above the power supply one and below the breakdown voltage of the component to be protected [1]. Given the constraints of the ESD design window, single SCRs [2] or NPN devices with strong snapback cannot be used or only in stacked configuration thus significantly degrading the on-state resistance of the resulting high voltage ESD protection and/or its area efficiency [3]. To cope with these issues, we propose an efficient nosnapback device. Using an optimized PNP transistor as a no-snapback ESD protection was already described in a previous work and specific design rules were defined [4]. One of the main drawback of PNPs is their much higher onresistance compared to their NPN counterparts [5]. In this work, the proposed protection, developed in the most advanced smart power technology of Freescale, consists in a structure combining an open-base lateral PNP bipolar transistor with a vertical diode within the same active silicon.

\section{DESIGN GUIDELINES FOR A PNP SELF-BIASED BIPOLAR TRANSISTOR}

When used as an ESD protection, a bipolar transistor is self-biased by the avalanche current of the base-collector junction. The physical parameters, which govern the snapback behavior, can be extracted from the analytical expression of the self-biased transistor. By making some simplifications (negligible recombination, no access resistance), an implicit bias equation (1) is obtained:

$$
\alpha M=1+\frac{I_{B}}{I_{E}}
$$

Where $\alpha$ is the common base gain (in self-biased configuration), $\mathrm{M}$ the avalanche multiplication factor, $I_{B}$ the current at base contact and $I_{E}$ the current at emitter contact.

Once the bipolar transistor triggers, its current characteristics snaps back to a lower voltage, called holding voltage, $I_{E}$ becomes much greater than $I_{B}$ and the on-state is equivalent to an open-base bias configuration. In particular, the holding voltage is determined by the two parameters $\alpha$ and $M$ when satisfying the following condition:

$$
\alpha \mathrm{M}=1
$$

Equation (2) shows that, to reduce the snapback (i.e. increase the holding voltage) two methods can be contemplated: lowering the gain $\alpha$ to increase the corresponding $\mathrm{M}$ value and then the voltage or use a device with a lower avalanche multiplication factor $\mathrm{M}$ so as condition (2) results in a higher holding voltage.

In general, NPN transistors are preferentially used as ESD protections for their very low onresistance $\left(\mathrm{R}_{\mathrm{ON}}\right)$. However, their high gain results in a strong snapback that is a major drawback to meet "high-voltage" specifications. One way, to solve this problem, is to replace the NPN by a PNP. Both, the differences in gain and multiplication factor tend to reduce the snapback. In general, PNP transistors exhibit a weak or no snapback. However, they have a serious handicap lying in their very much higher $\mathrm{R}_{\mathrm{ON}}$ related to the low mobility of holes carriers. In addition to this, high current injection effects occurring during an ESD stress induce a modulation of the space charge region leading to an electric field modification that results in an equivalent resistance. During an ESD 
stress, the current induced charge in the space charge region could be as high as $10^{18} \mathrm{~cm}^{-3}$. In smart power technologies, the doping levels are lower or in the range of this value, meaning that these high injection effects have a significant impact on the on-state resistance of the PNP device. A comparative study of the evolution of the current-induced charge into the base-collector space charge region allowed demonstrating a strong behavior difference between PNPs and NPNs [6]. As shown in Fig. 1, this evolution is similar in an NPN and a PNP as far as the current density is smaller than a critical current (Normalized current density =1). For higher values, the charge in an NPN monotonously increases, whereas the charge in a PNP decreases when a threshold current density is exceeded (Normalized current density $=5.4$ ).

For the case of the NPN transistor, the charge variation results in a continuous narrowing of the space charge region with current increase that tends to reduce the $\mathrm{R}_{\mathrm{ON}}$ and is beneficial for the ESD protection performance. In the case of a PNP, the charge decrease occurring at high current density results in the widening of the space charge region, which has a detrimental impact on the $\mathrm{R}_{\mathrm{ON}}$.

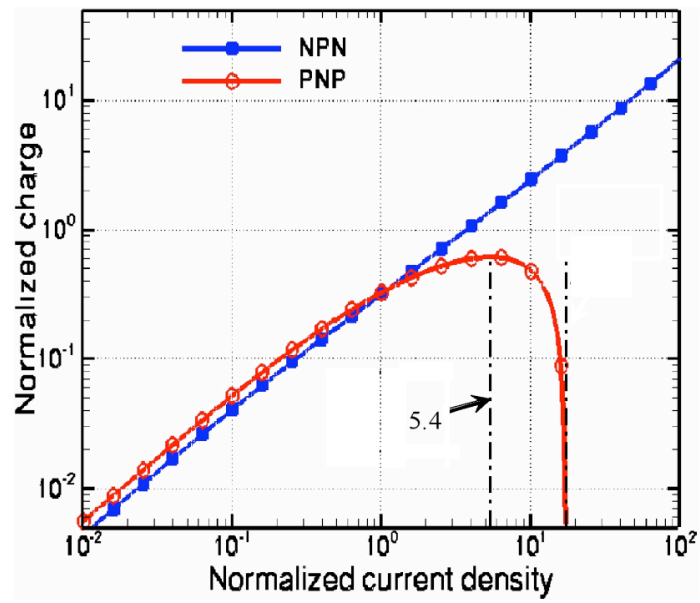

Fig. 1. Normalized current-induced charge in the basecollector space charge region versus normalized current density compared for NPN and PNP transistors [6].

PNPs were already explored as potential ESD protections but abandoned for this reason [3]. In a previous work [4], we defined four basic design rules to counterbalance the negative effects on $\mathrm{R}_{\mathrm{ON}}$ :

- Minimize emitter length: given the low current gain, no ballast is needed for thermal stability.

- Maximize emitter perimeter in front of the collector.

- Use a low base doping and an abrupt collector doping profile.

- Suppress the base contact: thanks to the low current gain, there is no issue of leakage current increase.
Practically, this implies inter-digitized, or matrix (circular, hexagonal) configurations.

Using such design guidelines, area-efficient ESD PNP-based ESD protections were developed to protect high voltage I/Os of a smart power technology. The results are shown in Fig. 2 and Table I. For all devices, a very high HBM robustness is achieved, and for three of them it exceeds the tester capability $(10 \mathrm{kV})$. The onresistance of the best device, DUT4, is $5 \Omega$ for a surface of $150 \times 100 \mu \mathrm{m}^{2}$.

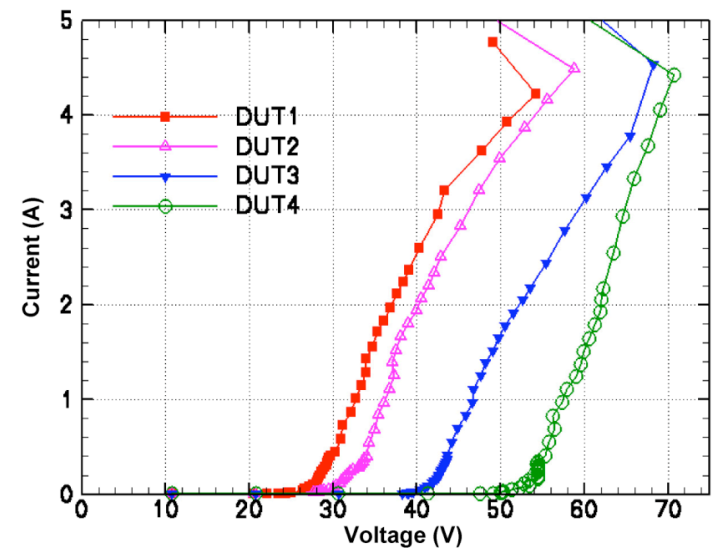

Fig. 2. TLP characteristics of four PNP-based ESD protection structures optimized for high voltage I/OS.

The obtained result is already satisfactory for protecting a $50 \mathrm{~V} \mathrm{I} / \mathrm{O}$ but not enough for protecting an $80 \mathrm{~V}$ one since it requires to stack two protections thus inducing a significant $R_{O N}$ degradation. We then studied a way to improve the $\mathrm{R}_{\mathrm{ON}}$ by implementing another current path in parallel with the PNP without increasing the footprint as described in the next section.

TABLE I

Results Of HBM AND MM Testing For The DEVICES OF FIG. 2.

\begin{tabular}{ccccc} 
& DUT1 & DUT2 & DUT3 & DUT4 \\
\hline $\mathrm{V}_{\mathrm{HBM}}(\mathrm{kV})$ & 9,5 & $\geq 10$ & $\geq 10$ & $\geq 10$ \\
$\mathrm{~V}_{\mathrm{HBM}} / \mathrm{S}\left(\mathrm{mV} \cdot \mu \mathrm{m}^{-2}\right)$ & 950 & $\geq 930$ & $\geq 760$ & $\geq 640$ \\
$\mathrm{~V}_{\mathrm{MM}}(\mathrm{V})$ & 350 & 400 & 500 & 650 \\
$\mathrm{~V}_{\mathrm{MM}} / \mathrm{S}\left(\mathrm{mV} \cdot \mu \mathrm{m}^{-2}\right)$ & 35 & 37 & 38 & 41
\end{tabular}

\section{PRINCIPLE AND OPTIMIZATION}

The proposed improved structure consists in a device combining an open-base lateral PNP bipolar transistor with a vertical diode within the same active silicon, as shown in Fig. 3. The technology is based on a P-type epi-layer on a $\mathrm{P}^{+}$substrate. An $\mathrm{N}^{+}$-buried layer and deep trenches provide insulation between the various active devices. The proposed PNP is composed of a deep P-type emitter diffused into the N-base that is left floating and the same deep P-diffusion is used as a collector. The avalanche diode is formed by the deep P-diffusion 
and the $\mathrm{N}^{+}$-buried layer. Rigorously, in a floating base configuration, the diode is a vertical PNP transistor; however its base doping level is too high for a significant current gain. Hence the vertical structure can be reasonably approximate as a PN diode.

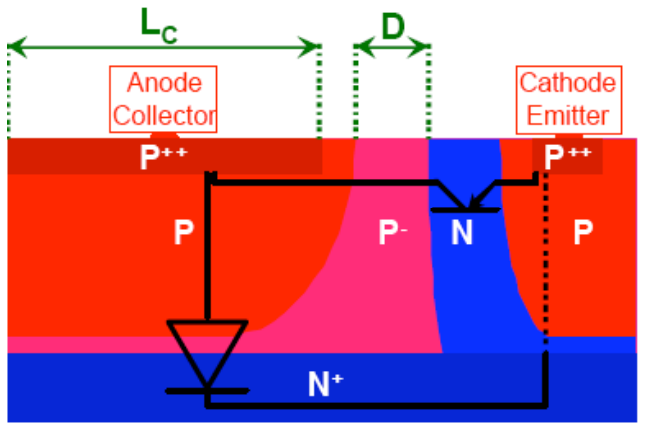

Fig. 3. Schematic cross-section of the lateral PNP transistor coupled to a vertical diode within the same structure.

Due to the non-snapback characteristics of the floating base transistor and the avalanche diode, both devices can operate concurrently and in parallel, provided that the PNP base-collector and the diode breakdown voltages are in the same range. As shown by the simulation result in Fig. 4, there are two current flows into the active silicon bulk, then allowing a significant $\mathrm{R}_{\mathrm{ON}}$ reduction. Moreover, the most important feature concerning the $\mathrm{R}_{\mathrm{ON}}$ reduction is the diode current contribution to the PNP bias current, leading to a great improvement of the current injection. In this arrangement, it has to be noticed that the diode is not implemented to help the PNP transistor triggering but to improve the on-state characteristics of the protection.

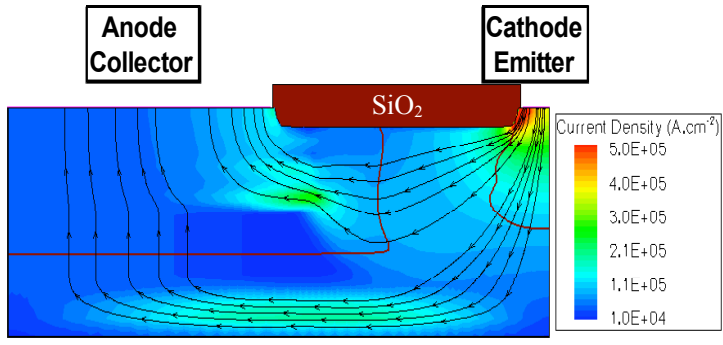

Fig. 4. Current density distribution, showing a lateral (PNP) and vertical (diode) current paths.

To take full advantage of this new feature, we can further minimize $\mathrm{R}_{\mathrm{ON}}$, through the optimization of the collector width $\mathrm{L}_{\mathrm{C}}$ (Fig. 3), as it should be sufficiently wide to provide an important diode current without being detrimental to the total protection area. The second optimization consists in matching breakdown voltages of the PNP and the diode by adjusting the lateral distance D (Fig. 3). Regarding the diode breakdown voltage, the vertical doping profiles provided are technology defined. Fig. 5.a shows the impact of the $\mathrm{L}_{\mathrm{C}}$ distance on the $\mathrm{R}_{\mathrm{ON}}$. This parameter controls the diode area and then the maximum current it can handle. In this structure, the PNP breakdown voltage is not optimized (D distance) and it triggers before the diode at $30 \mathrm{~V}$; that explains the first high $\mathrm{R}_{\mathrm{ON}}(\sim 20 \Omega)$. When the diode triggers at $55 \mathrm{~V}$, the $\mathrm{R}_{\mathrm{ON}}$ greatly improves and ranges from 7.4 to $2.4 \Omega$ depending on $\mathrm{L}_{\mathrm{C}}$. As expected, the failure current depends on the diode size. In addition, it was observed that increasing $\mathrm{L}_{\mathrm{C}}$ beyond a certain value does not improve the $\mathrm{R}_{\mathrm{ON}}$ value but allows increasing the failure current. Fig. 5.b presents the results for the optimization of the PNP breakdown voltage to make it trigger at about the same voltage as the diode. The larger distance $\mathrm{D}$ allows a concurrent triggering of both diode and PNP and thus directly entering into the low $\mathrm{R}_{\mathrm{ON}}$ regime at turn-on. In this case, the triggering voltage can be adjusted without modifying the failure current that is an interesting property regarding the manufacturability. This trend is confirmed by the HBM and MM testing as summarized in Table II.

\section{TABLE II}

IMPACT OF DISTANCE D ON THE HBM AND MM ROBUSTNESS $\left(\mathrm{L}_{\mathrm{C}}=18.3\right.$ a.u.).

\begin{tabular}{cccc}
$\mathrm{D}($ a.u. $)$ & 7.03 & 8.5 & 9.97 \\
\hline $\mathrm{V}_{\mathrm{HBM}}(\mathrm{kV})$ & 8.0 & 7.0 & 9.5 \\
$\mathrm{~V}_{\mathrm{HBM}} / \mathrm{S}\left(\mathrm{mV} . \mu \mathrm{m}^{-2}\right)$ & 680 & 570 & 740 \\
$\mathrm{~V}_{\mathrm{MM}}(\mathrm{V})$ & 500 & 500 & 450 \\
$\mathrm{~V}_{\mathrm{MM}} / \mathrm{S}\left(\mathrm{mV} . \mu \mathrm{m}^{-2}\right)$ & 42 & 41 & 35
\end{tabular}

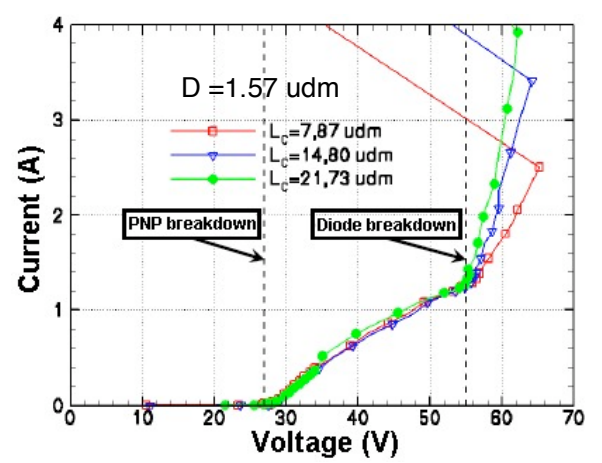

(a)

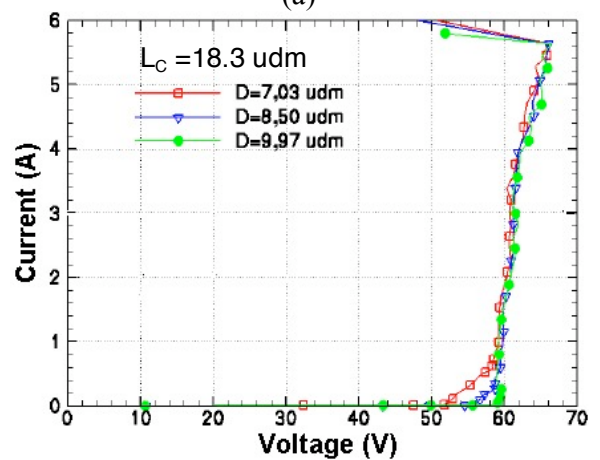

(b)

Fig. 5. TLP measurements showing the impact of the collector width $\mathrm{L}_{\mathrm{C}}$ (a) and the distance $\mathrm{D}$ (b). 
To evaluate the contribution of this coupling, we compared by simulation the currents of the standalone PNP, the standalone diode, the isolated PNP and diode in parallel and the coupled PNPdiode. It resulted that the current of the coupled PNP-diode is not the same as the one of the isolated devices in parallel. The coupling results in a significant current increase ranging from $41 \%$ to $58 \%$ compared to using the two isolated devices in parallel.

\section{MEASUREMENTS AND APPLICATION}

The TLP characteristics of two improved structure are shown in Fig. 6 and compared with the optimized PNP DUT4 of Fig.2 [4]. A $\mathrm{R}_{\mathrm{ON}}$ reduction by a factor seven is observed: 0.7 $\mathrm{m} \Omega . \mathrm{cm}^{2}$ for DUT4 and $0.1 \mathrm{~m} \Omega . \mathrm{cm}^{2}$ for the improved PNP-diode component. Thanks to this low on-resistance, its measured HBM robustness is $8 \mathrm{kV}$ for a $100 \mathrm{x} 100 \mu \mathrm{m}^{2}$ silicon area.

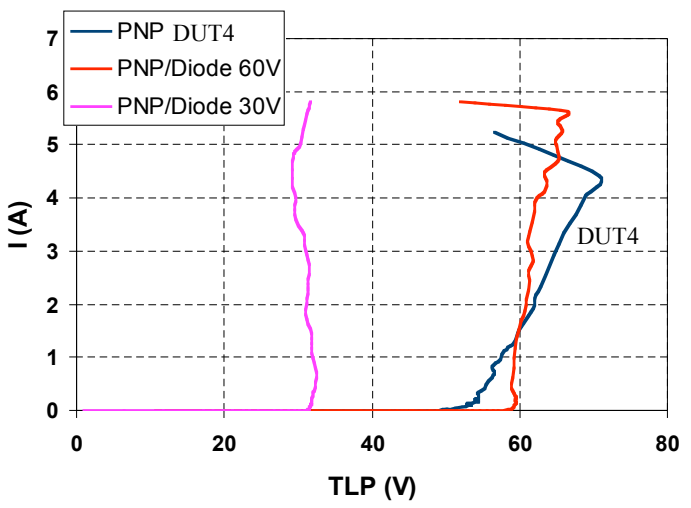

Fig. 6. TLP characteristics of two optimized PNPdiode structures (30V and $60 \mathrm{~V}$ clamping voltage) and of a standalone optimized PNP (DUT4 of Fig. 2).

Using this approach, PNP-diode protection devices with $30 \mathrm{~V}$ and $60 \mathrm{~V}$ clamping voltages were optimized (Fig.6) and taken advantage to develop a protection for a Power-Over-Ethernet application featuring an $80 \mathrm{~V}-100 \mathrm{~V}$ design window for $2 \mathrm{kV}$ HBM robustness. Stacking two devices with appropriate clamping voltages $(30 \mathrm{~V}$ and $60 \mathrm{~V})$ allowed meeting this specification as shown in Fig.7. The resulting on-resistance is $6.4 \Omega$ for a total surface of $151 * 140 \mu \mathrm{m}^{2}$, which corresponds at least to half of the surface required for a standard protection based on stacked NPN transistors. The HBM and MM robustness of the standalone structure is $6 \mathrm{kV}$ and $650 \mathrm{~V}$, respectively. To protect a device within the design window, the maximum HBM stress level is in the range of $2.5 \mathrm{kV}$.

\section{CONCLUSION}

In this paper, we have demonstrated that a PNPbased protection structure can be greatly improved to provide a high ESD robustness for high voltage I/Os in an advanced smart power technology. By using specific design guidelines and coupling an open-base lateral PNP with a vertical avalanche diode, a low on-resistance $(1 \Omega)$ can be obtained with a limited silicon area. This optimized structure was advantageously used to protect specific high voltage pins of a Power-Over-Ethernet chip.

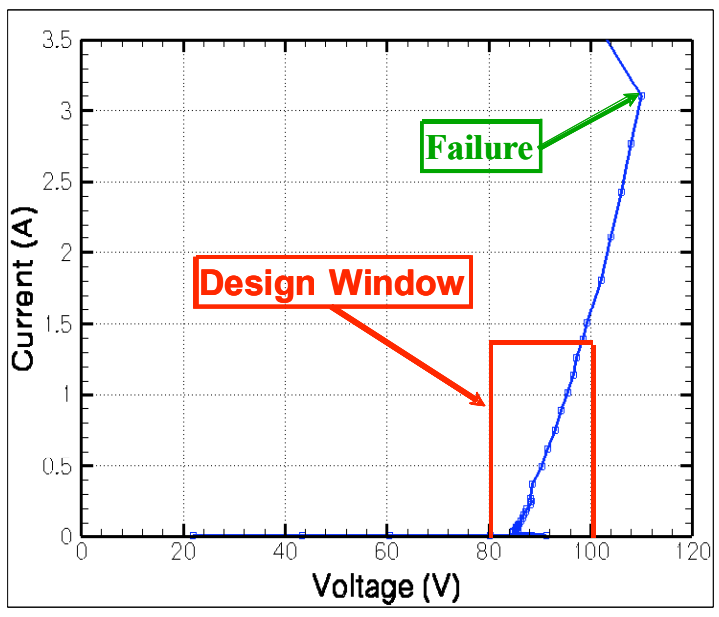

Fig. 7. TLP characteristics of the optimized protection for a Power-Over-Ethernet application using two stacked PNP-diode structures of $30 \mathrm{~V}$ and $60 \mathrm{~V}$ clamping voltages.

\section{REFERENCES}

[1] M.P.J. Mergens, M.T. Mayerhofer, J.A. Willemen, M. Stecher, "ESD Protection Considerations in Advanced High-Voltage Technologies for Automotive", in Proc. EOS/ESD Symposium, pp. 54-63, September 2006.

[2] V.A. Vashchenko, P. Lindorfer, P. Hopper, "Implementation of High VT Turn -on in LowVoltage SCR Devices “, in Proc. EOS/ESD Symposium, 2005.

[3] M -D. Ker, K-H. Lin, "The Impact of LowHolding-Voltage and the Design of Latch-up Free Power-Rail ESD Clamp Circuit for LCD Drivers ICs “, IEEE Journal of Solid State Circuit, vol. 40, n 8 , pp1751-59, August 2005.

[4] A. Gendron, P. Renaud, P. Besse, C. Salamero, M. Bafleur, N. Nolhier, "Area-Efficient Reduced and No-Snapback PNP-based ESD Protection in Advanced Smart Power Technology", in Proc. EOS/ESD Symposium, Sep. 2006, pp. 69-76.

[5] J. Li, R. Gauthier, K. Chatty, D. Kontos and al., "PMOSFET-based ESD Protection in $65 \mathrm{~nm}$ Bulk CMOS Technology for Improved External Latch-up Robustness", in Proc. EOS/ESD Symposium, 2005.

[6] A. Gendron, P. Renaud, M. Bafleur and N. Nolhier, Analytical description of the injection ratio of selfbiased bipolar transistors under the very high injection conditions of ESD events, to be published in Solid State Electronics. 